\title{
Methotrexate in Crohn's disease
}

\author{
D S Rampton
}

A minority of patients with Crohn's have disease refractory to or dependent on corticosteroids who are inappropriate for surgery; most will also have failed to respond to aminosalicylates, antibiotics, and/or a liquid formula diet. Firstline immunomodulatory therapy, given to initiate and maintain remission and allow tapering of steroid therapy, is usually azathioprine or 6-mercaptopurine. Unfortunately, approximately $20 \%$ of patients are resistant to or intolerant of thiopurines, and their management provides a difficult therapeutic challenge. The possible benefits of mycophenolate mofetil are unconfirmed, while infliximab is expensive and unproved in its long term efficacy and safety.

Methotrexate is of proven value in psoriasis and rheumatoid arthritis. ${ }^{12}$ Since its effects in Crohn's disease were first reported in an open trial 12 years ago, ${ }^{3}$ several uncontrolled and five controlled studies have further defined its role. ${ }^{4-8}$

\section{Mechanism of action}

Methotrexate and its breakdown products inhibit several enzymes in the metabolic pathway of folic acid. ${ }^{9}$ While the cytotoxic and antiproliferative effects of high dose methotrexate are ascribed to inhibition of dihydrofolate reductase, with consequent inhibition of DNA, RNA, and protein synthesis, the antiinflammatory and immunomodulatory actions of low doses are probably due to inhibition of other folate dependent enzymes. Long term low dose methotrexate may lead to accumulation of adenosine, a lymphotoxic, immunosuppressive, and anti-inflammatory autocoid. Other effects include interleukin 1 (IL-1) receptor blockade, increased production of the regulatory cytokine IL-2, decreased production of soluble IL-2 receptors, IL-6, IL-8, leucotriene B4, and antibodies, and impairment of neutrophil chemotaxis.

\section{Efficacy}

The reported controlled trials differ in patient selection and numbers, dose, route and duration of methotrexate therapy, concurrent treatment, and outcome measures. ${ }^{4-8}$

The two largest studies compared methotrexate with placebo in the induction and maintenance of remission. ${ }^{4}{ }^{8}$ In the first study, of 94 patients with steroid resistant or steroid dependent Crohn's disease given methotrexate $25 \mathrm{mg} /$ week intramuscularly with

Academic Department of Adult and Paediatric Gastroenterology, St Bartholomew's and the Royal London School of Medicine and Dentistry, Turner St, London E1 2AD, UK

Correspondence to: Dr D S Rampton, Department of Gastroenterology, Royal London Hospital, London E11BB, UK. drampton@mds.qmw.ac.uk tapering of oral prednisolone for 16 weeks, 39\% entered remission compared with $19 \%$ given placebo $(\mathrm{p}=0.025$, relative risk 1.95 (95\% confidence intervals (CI) 1.09-3.48)). ${ }^{4}$ Subsequently, methotrexate $15 \mathrm{mg} /$ week intramuscularly for 40 weeks maintained remission in $65 \%$ of 40 patients compared with $39 \%$ of patients given placebo $(\mathrm{p}=0.04$, reduction in risk of relapse $26 \%, 95 \%$ CI $4-48 \%$ ); use of prednisolone was halved. ${ }^{8}$

The other published controlled trials are much smaller. In a dose-response study, only $17 \%$ of 32 patients given 15 or $25 \mathrm{mg} /$ week subcutaneous methotrexate achieved remission by 16 weeks ${ }^{6}$ while $12.5 \mathrm{mg} /$ week given orally was no more effective than placebo in either inducing (26 patients) or maintaining (10 patients) remission. ${ }^{5}$ Lastly, 15-22.5 mg/week methotrexate given orally in three divided doses for up to one year maintained remission in $54 \%$ of 13 patients given methotrexate compared with $20 \%$ of patients who received placebo $(\mathrm{p}=0.06){ }^{7}$

\section{Side effects}

The potential benefits of methotrexate must be weighed against its side effects. Rash, nausea, diarrhoea, stomatitis, and other gastrointestinal symptoms necessitate its discontinuation in approximately $5 \%$ of patients. There are case reports of severe colitis complicating the use of methotrexate, although not yet in patients with Crohn's disease. ${ }^{9}$ There is an increased risk of opportunistic infections, including herpes zoster and pneumocystis carinii pneumonia, but not of neoplasia other than lymphoproliferative disorders. ${ }^{10}$ The latter are related to previous infection with Epstein-Barr virus, and are sometimes reversible on methotrexate withdrawal. Because methotrexate is teratogenic, pregnancy or conception within six months of stopping treatment with methotrexate of either partner should be avoided. Breast feeding is also contraindicated.

Bone marrow depression occurs in up to $20 \%$ of patients with rheumatoid arthritis receiving low dose methotrexate but is usually reversible on stopping the drug or reducing the dose. Blood counts weekly initially and then every two months are mandatory. Risk factors include coadministration of other antifolate agents such as trimethoprim-sulphamethoxazole, and nonsteroidal anti-inflammatroy agents, penicillins, old age, and renal impairment, all of which reduce excretion of methotrexate. Concurrent long term folic acid reduces the incidence of cytopaenias, stomatitis, and other digestive symptoms, without compromising the efficacy of methotrexate. ${ }^{9}$

The risk of methotrexate induced hepatic fibrosis is higher in psoriasis than rheumatoid arthritis ${ }^{11}$; limited data suggest that hepatotoxicity may be rare in Crohn's disease. However, it is prudent to exclude from 


\section{THERAPY UPDATE}

\section{Key points}

- Methotrexate given intramuscularly can be used to achieve (25 mg/week) and maintain (15 $\mathrm{mg} /$ week) remission in patients with steroid refractory or steroid dependent Crohn's disease.

- Potential side effects include bone marrow depression, infections, teratogenicity, hepatic fibrosis, and pneumonitis.

- Contraindications to methotrexate include liver and renal disease, alcohol, obesity, diabetes, infections, actual or possible pregnancy, and malignancy.

- Patients given methotrexate require careful follow up and monitoring, including full blood count and liver function tests every 1-2 months.

- Further trials are needed to clarify the indications, dose, route, and duration of therapy with methotrexate.

treatment patients who drink $>7$ units of alcohol/week, weigh $>40 \%$ normal, or have diabetes. ${ }^{11}$ Serum transaminases and albumin should be checked every 1-2 months, and liver biopsy undertaken in patients with persistently abnormal values ${ }^{11}$; biopsy should also be considered after a cumulative dose of $1.5 \mathrm{~g} .{ }^{9}$

Hypersensitivity pneumonitis occurs in up to $10 \%$ of rheumatoid patients given methotrexate. Cough or dyspnoea should prompt chest $x$ ray, blood gases, and lung function tests, particularly carbon monoxide diffusing capacity. ${ }^{9}$

\section{Conclusions}

Although North American trials ${ }^{4} 8$ suggest that methotrexate may have a valuable role in selected patients with steroid refractory or steroid dependent Crohn's disease, there are unanswered questions. The minimum effective dose is unclear, available data indicating 25 mg weekly intramuscularly to induce and $15 \mathrm{mg}$ weekly intramuscularly to maintain remission. ${ }^{48}$ Oral administration of methotrexate seems to increase the incidence of gastrointestinal side effects, particularly within 24 hours of dosing, but would be more convenient than injections if proven efficacious. While absorption of low dose oral methotrexate in Crohn's disease, even in patients with severe small bowel disease or resections, appears satisfactory, ${ }^{12}$ a trial of enteral versus parenteral administration would be helpful. Exactly when to use methotrexate is uncertain. In steroid resistant or steroid dependent patients, should we use first a thiopurine, methotrexate, or mycophenolate? We also need to know whether, as in rheumatoid arthritis, methotrexate is more effective in combination with other therapies, such as infliximab. ${ }^{13}$ There is a clear requirement for further trials to clarify how best to use methotrexate in Crohn's disease.

1 Willkens RF, Williams HJ, Ward JR, et al. Randomised, double-blind, placebo controlled trial of low-dose pulse methotrexate in psoriatic placebo controlled trial of low-dose pulse
arthritis. Arthritis Rheum 1984;27:376-81.

2 Weinblatt ME, Coblyn JS, Fox DA, et al. Efficacy of low-dose methotrexate in rheumatoid arthritis. $\mathrm{N} \mathrm{Engl} \mathrm{f} \mathrm{Med} \mathrm{1985;312:818-22.}$ 3 Kozarek RA, Patterson DJ, Gelfand ND, et al. Methotrexate induces clinical and histologic remission in patients with refractory inflammatory bowel disease. Ann Intern Med 1989;110:353-6.

4 Feagan BG, Rochon J, Fedorak RN, et al. Methotrexate for the treatment of Crohn's disease. N Engl f Med 1995;332:292-7.

5 Oren R, Moshkowitz M, Odes S, et al. Methotrexate in chronic active Crohn's disease: a double-blind, randomised, Israeli multicentre trial. Am f Gastroenterol 1997;92:2203-9.

6 Egan LJ, Sandborn WJ, Tremaine WJ, et al. A randomised dose-response and pharmacokinetic study of methotrexate for refractory inflammatory Crohn's disease and ulcerative colitis. Aliment Pharmacol Ther 1999;13:1597-604.

7 Arora S, Katkov W, Cooley J, et al. Methotrexate in Crohn's disease: results of a randomised, double-blind, placebo-controlled trial. Heparesults of a randomised, double-b

8 Feagan BG, Fedorak RN, Irvine EJ, et al. A comparison of methotrexFeagan BG, Fedorak RN, Irvine EJ, et al. A comparison of methotrexate with placebo for the maintenance

9 Egan LJ, Sandborn WJ. Methotrexate for inflammatory bowel disease: pharmacology and preliminary results. Mayo Clin Proc 1996;71:69-80. 0 Kanik KS, Cash JM. Does methotrexate increase the risk of infection or malignancy? Rheum Dis Clin North Am 1997;23:955-67.

11 Kremer JM, Alarcon GS, Lightfoot RW, et al. Methotrexate for rheumatoid arthritis: suggested guidelines for monitoring liver toxicity: American College of Rheumatology. Arthritis Rheum 1994;37:316-28.

12 Moshkowitz M, Oren R, Tishler M, et al. The absorption of low-dose methotrexate in patients with inflammatory bowel disease. Aliment Pharmacol Ther 1997;11:569-73

13 Maini R, St Clair EW, Breedveld F, et al. Infliximab (chimeric anti-tumour necrosis factor alpha monoclonal antibody) versus
placebo in rheumatoid arthritis patients receiving concomitant methotrexate: a randomised phase III trial. Lancet 1999;354:1932-9. 